OPEN ACCESS

Edited by:

Rosa Gomez-Villafuertes,

Complutense University of Madrid,

Spain

Reviewed by:

Yoshinori Moriyama,

Matsumoto Dental University,

Japan

Chilman Bae,

Southern Illinois University

Carbondale, United States

*Correspondence:

Lin-Hua Jiang

I.h.jiang@/eeds.ac.uk

tThese authors have contributed equally to this work

Specialty section:

This article was submitted to Experimental Pharmacology and Drug Discovery,

a section of the journal

Frontiers in Pharmacology

Received: 09 August 2019 Accepted: 15 October 2019 Published: 06 November 2019

Citation:

Wei L, Mousawi F, Li D, Roger S, Li J, Yang X and Jiang L-H (2019) Adenosine Triphosphate Release and P2 Receptor Signaling in

Piezo1 Channel-Dependent Mechanoregulation.

Front. Pharmacol. 10:1304. doi: 10.3389/fphar.2019.01304

\section{Adenosine Triphosphate Release and P2 Receptor Signaling in Piezo1 Channel-Dependent Mechanoregulation}

\author{
Linyu Wei ${ }^{1+}$, Fatema Mousawi ${ }^{2 t}$, Dongliang $\mathrm{Li}^{3}$, Sébastien Roger ${ }^{4}$, Jing $\mathrm{Li}^{5}$, Xuebin Yang ${ }^{6}$ \\ and Lin-Hua Jiang ${ }^{1,2,4 *}$ \\ ${ }^{1}$ Sino-UK Joint Laboratory of Brain Function and Injury and Department of Physiology and Neurobiology, Xinxiang Medical \\ University, Xinxiang, China, ${ }^{2}$ School of Biomedical Sciences, Faculty of Biological Sciences, University of Leeds, Leeds, \\ United Kingdom, ${ }^{3}$ Department of Physiology, Sanquan College of Xinxiang Medical University, Xinxiang, China, ${ }^{4}$ EA4245, \\ Transplantation, Immunology and Inflammation, Faculty of Medicine, University of Tours, Tours, France, ${ }^{5}$ Lingnan Medical \\ Research Centre, School of Medicine, Guangzhou University of Chinese Medicine, Guangzhou, China, ${ }^{6}$ Department of Oral \\ Biology, Faculty of Medicine and Health, University of Leeds, Leeds, United Kingdom
}

Organs and tissues and their constituent cells are physiologically submitted to diverse types of mechanical forces or stress, one common sequence of which is release of intracellular ATP into extracellular space. Extracellular ATP is a well-established autocrine or paracrine signaling molecule that regulates multiple cell functions and mediates cell-tocell communications via activating the purinergic P2 receptors, more specifically, ligandgated ion channel P2X receptors and some of the G-protein-coupled P2Y receptors. The molecular mechanisms that sense mechanical and transduce forces to trigger ATP release are poorly understood. The Piezo1, a newly identified mechanosensing ion channel, shows widespread expression and confers mechanosensitivity in many different types of cells. In this mini-review, we briefly introduce the Piezo1 channel and discuss the evidence that supports its important role in the mechanoregulation of diverse cell functions and, more specifically, critical engagement of ATP release and subsequent P2 receptor activation in Piezo1 channel-dependent mechanoregulation. Such ATP release-mediated coupling of the Piezo1 channel and P2 receptors may serve a signaling mechanism that is more common than we currently understand in transducing mechanical information to regulation of the attendant cell functions in various organs and tissues.

Keywords: mechanical stimuli, mechanosensitive cells, Piezo1 channel, adenosine triphosphate release, P2 receptors

\section{INTRODUCTION}

Adenosine triphosphate (ATP), while it is best known for its intracellular role as the cellular energy source, gains increasing recognition as an extracellular signaling molecule when it is released into extracellular spaces. In mammalian cells, the ATP-based signaling system comprises of three principal components: release of intracellular ATP into the extracellular space, activation of the ligand-gated ion channel P2X receptors and/or G-protein-coupled P2Y receptors for extracellular ATP, and removal of extracellular ATP to terminate its action by a broad family of ATP-scavenging 
ecto-nucleotidases that convert ATP to ADP, adenosine monophosphate, or adenosine (Figure 1) (Verkhratsky and Burnstock, 2014; Jiang et al., 2017a). This system represents one of the most common signaling mechanisms regulating cell functions and mediating cell-to-cell communications and plays a critical role in a wide range of physiological processes, such as hearing, tasting, nociception, immune responses, muscle contraction, learning, and memory. There exists a large volume of evidence that alterations in such an ATP-based signaling system contribute in the pathogenesis and progression of diverse conditions, ranging from hearing loss, pain, inflammatory diseases, hypertension, neurodegenerative diseases, and psychotic disorders to cancer metastasis (North, 2002; Fields and Burnstock, 2006; Khakh and North, 2006; Abbracchio et al., 2009; Surprenant and North, 2009; Zimmermann et al., 2012; Caseley et al., 2014; Roger et al., 2015; Cekic and Linden, 2016; Krugel, 2016; Alves et al., 2018; Di Virgilio et al., 2018; Wei et al., 2018).

It is conceivable that ATP easily leaks from damaged or dying cells as a danger signal alerting tissue damage and inflammation. However, decades of studies provide clear evidence to show that many types of cells can release ATP without compromise in cell viability and a variety of physical and chemical signals or stimuli can induce non-lytic release of ATP. Two general release pathways, namely, vesicular and diffusion, have been proposed for efflux of intracellular ATP (Verkhratsky and Burnstock, 2014). However, the molecular mechanisms mediating ATP release are still not fully elucidated, in part due to that such mechanisms appear to be diverse and cell-type specific. Furthermore, many types of cells are equipped with multiple ATP release mechanisms and deploy them according to the nature of the incoming stimuli. Vesicular release via exocytosis represents the major mechanism by which neurons release ATP into the synaptic cleft in the peripheral and central nervous systems (Pankratov et al., 2006; Abbracchio et al., 2009; Masuda et al., 2016). Vesicular ATP release via exocytosis has been also described in astrocytes (Chen et al., 2013; Lalo et al., 2014), urothelial cells (Nakagomi et al., 2016), neutrophils (Harada et al., 2018), and pancreatic $\beta$-cells (Geisler et al., 2013; Sakamoto et al., 2014). In this regard, it is worth mentioning that the vesicular nucleotide transporter (VNUT) plays a critical role in mediating vesicular storage and thereby subsequent release of ATP (Sawada et al., 2008) (for more details, see Moriyama et al., 2017; Miras-Portugal et al., 2019). On the other hand, several distinctive types of ion channels have been suggested to act as conduits permitting diffusion of ATP out of cells. The volumeregulated anion channel (VRAC) has been identified to mediate non-synaptic release of ATP from axons in response to action potential-induced swelling (Fields and Ni, 2010). The pannexin hemi-channels, calcium homeostasis modulator 1 (CALHM1), cystic fibrosis transmembrane conductance regulator (CFTR), maxi-anion channel, and P2X7 receptor as well as the VRAC have been reported to mediate or regulate ATP efflux from a variety of non-neuronal cells. For detailed discussion of these ATP release mechanisms, the readers can consult recently published reviews (e.g., Verkhratsky and Burnstock, 2014; Taruno, 2018).

Cells are physiologically submitted to diverse types of mechanical forces or stress and virtually all types of cells exhibit a mechanosensitivity. They can sense external or "outside-in" mechanical forces, for example, fluid flow-induced shear stress, osmotic stress, and pressure-induced membrane stretch (Nourse and Pathak, 2017). Cells can also generate traction forces via actin-myosin interactions at the focal adhesion zones and apply such "inside-out" mechanical forces to survey the mechanical and geographical properties of extracellular matrix and cellsupporting substrates (Nourse and Pathak, 2017; Ellefsen et al., 2019). Importantly, cells are able to convert mechanical forces into intracellular signals and even integrate mechanical information into the genomic blueprint (Choi et al., 2019), indicating that mechanical stimulation can have long-term effects as well as short-term effects on cell functions. Mechanical stimuli are long known as a potent trigger for non-cytolytic release of ATP both in vivo and in vitro, and accumulating evidence supports that
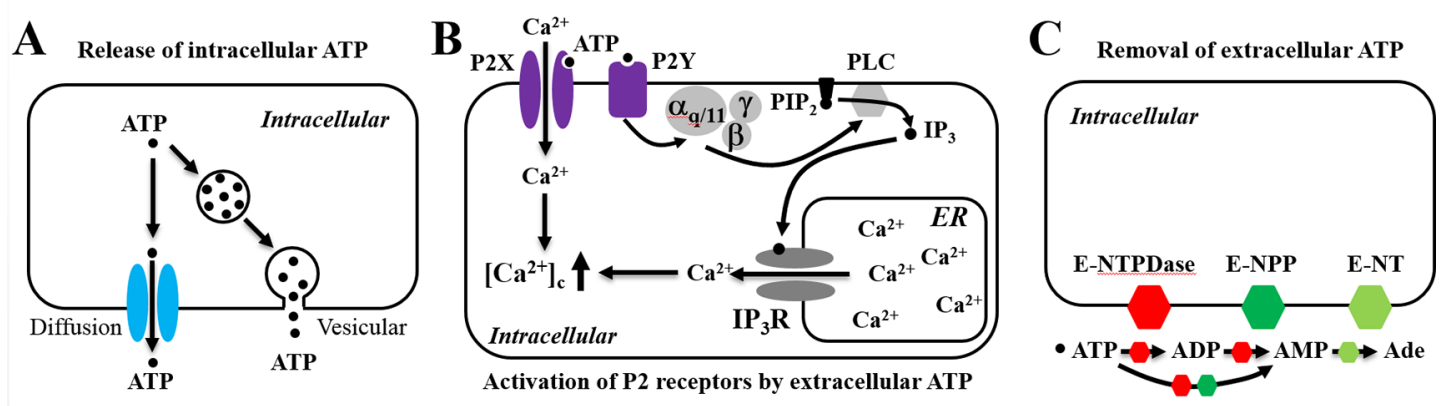

FIGURE 1 | Schematic illustration of the adenosine triphosphate (ATP)-based signaling system in mammalian cells. The ATP-based signaling system comprises of the following three principal components. (A) Release of intracellular ATP, which occurs via exocytosis (vesicular) and/or diffusion through many different types of ion channels. (B) Extracellular ATP as an autocrine or paracrine signal activating ligand-gated ion channel P2X receptors and/or G-protein-coupled P2Y receptors. ATP gates all P2X receptor ion channels, allowing extracellular $\mathrm{Ca}^{2+}$ influx. Alternatively, ATP activates the P2Y receptors, mainly P2Y, $\mathrm{P}^{2} \mathrm{Y}_{2}$, and P2Y ${ }_{11}$, leading to sequential activation of $\mathrm{G}_{\alpha, q / 11}$, phospholipase $\mathrm{C}(\mathrm{PLC})$, conversion of membrane lipid phosphatidylinositol 4,5-bisphosphate (PIP $\left.{ }_{2}\right)$ to inositol triphosphate (IP , and $_{3}$ diacylglycerol (not depicted), activation of the $\mathrm{IP}_{3}$ receptor $\left(\mathrm{IP}_{3} \mathrm{R}\right)$, and $\mathrm{Ca}^{2+}$ release from the endoplasmic reticulum (ER). (C) Termination of the actions of ATP by converting to ADP, AMP, and adenosine (Ade) by ecto-nucleotidases, including ecto-nucleoside triphosphate diphosphohydrolase (E-NTPDase), ecto-nucleotide pyrophosphatase/phosphodiesterase (E-NPP), and by ecto-5'-nucelotidase (E-NT). 
ATP release and subsequent activation of the $\mathrm{P} 2$ receptors act as a crucial signal transduction mechanism in the mechanoregulation of cell functions (Petruzzi et al., 1994; Riddle et al., 2007; Wan et al., 2008; Yu et al., 2010; Sun et al., 2013; Miyamoto et al., 2014; Weihs et al., 2014; Cinar et al., 2015; Wang et al., 2016; Iring et al., 2019). However, the molecular identity of the mechanosensor that directly detects the mechanical forces and triggers ATP release remained elusive. The Piezo1 ion channel has emerged as an intrinsically mechanically activated $\mathrm{Ca}^{2+}$-permeable cation channel that confers cells with an ability of sensing diverse forms of mechanical stimuli (Murthy et al., 2017; Wu et al., 2017; Xiao, 2019). Furthermore, a large number of recent studies have shown an important role of the Piezol channel in the mechanoregulation of a wide range of physiological and pathological functions (Murthy et al., 2017; Wu et al., 2017; Xiao, 2019). Of interest, accumulating evidence supports that ATP release and P2 receptor signaling are important in mediating Piezol channel-dependent mechanoregulation. The two separate domains of investigation thus need to join forces in order to develop a full and mechanistic understanding of mechanoregulation. The aim of this minireview is to introduce the Piezol channel and discuss the recent studies that provide evidence to support its crucial role in several types of mechanosensitive cells in the induction of ATP release and subsequent activation of the $\mathrm{P} 2 \mathrm{X}$ or $\mathrm{P} 2 \mathrm{Y}$ receptors and the mechanoregulation of the attendant cell functions. With increasing evidence to show their overlapping expression in many different types of mechanosensitive cells, the Piezo1 channel and $\mathrm{P} 2$ receptors, via coupling by ATP, may serve as a signaling mechanism that is more common than we currently understand in transducing the mechanical information to functional regulation.

\section{A Brief Introduction to the Piezo1 Channel}

The Piezol protein (also known as Fam38a) was identified to form the mechanically activated ion channel mediating pressureinduced ionic currents in mouse neuroblastoma Neuro2A cells (Coste et al., 2010; Coste et al., 2012; Syeda et al., 2016). In the same seminal study, a homologue protein, Piezo2 (also known as Fam38b), was found to express in a subset of mouse dorsal root ganglia neurons and can also form a mechanically activated ion channel with comparatively faster inactivation kinetics. The Piezo proteins are large in size, being 2,500-2,800 amino acid residues long and with predicted molecular weights of $\sim 290-320 \mathrm{kDa}$ for the mouse and human proteins. They are predicted to have a unique membrane topology composed of 38 transmembrane segments and intracellular $\mathrm{N}$ - and C-termini (Zhao et al., 2019). Several structures containing the core parts of the mouse Piezo1 channel have been recently determined by cryo-electron microscopy (Saotome et al., 2018; Zhao et al., 2018; Wang et al., 2019). These structures reveal a trimeric assembly and a three-bladed propeller-like architecture of the Piezo1 channel. For further structural details, the readers can consult recently published reviews (e.g., Murthy et al., 2017; Xiao, 2019; Zhao et al., 2019).

Studies have demonstrated wide expression of the Piezol channel that enables many different types of cells to sense a diversity of "outside-in" mechanical forces, including indentation, membrane stretch, shear stress, osmotic stress, ultrasound, and compression (Coste et al., 2010; Li et al., 2014; Miyamoto et al., 2014; Pathak et al., 2014; Ranade et al., 2014; Jin et al., 2015; Lewis and Grandl, 2015; Syeda et al., 2016; Wang et al., 2016; Gao et al., 2017; Wu et al., 2017). There is also compelling evidence to suggest that the Piezo1 channel can be activated by traction forces (Pathak et al., 2014; Murthy et al., 2017; Nourse and Pathak, 2017; Ellefsen et al., 2019). Thus, two different, so-called "force-from-lipids" and "force-from-filaments," mechanisms have been proposed for mechanical activation of the Piezol channel (Murthy et al., 2017). In the "force-from-lipids" mechanism, mechanical forces introduce membrane tension that leads to reorganization of lipids within and surrounding the channel proteins. The resultant alterations in the membrane lipid-channel protein interactions induce the channel to open. This gating mechanism has gained support from a recent study (Lin et al., 2019). The "force-from-filaments" mechanism proposes that the interactions between the channel and extracellular matrix or intracellular cytoskeletal proteins provoke conformational changes leading to the channel opening.

The mechanically activated ion channels are less amenable to electrophysiological studies as compared to the ion channels activated by other modalities, such as changes in membrane potential, temperature, or chemical ligands. This is in part because of the unease of applying mechanical stimuli to cells under the experimental settings and the challenge of accurately determining the mechanical forces inducing the channel activation (Parpaite and Coste, 2017). Yoda1, a synthetic chemical, selectively activates the Piezol channel with an $\mathrm{EC}_{50}$ (the concentration evoking $50 \%$ of the maximal response) of $2.5-27 \mu \mathrm{M}$, determined by measuring Yoda1-induced $\mathrm{Ca}^{2+}$ responses in cells expressing the recombinant mouse and human Piezol channels (Syeda et al., 2015; Evans et al., 2018). The discovery of Yoda1 has made it technically more approachable to the study of the Piezol channel under in vitro conditions. Grammostola spatulata mechanotoxin 4 (GsMTx4), a 34-amino acid peptide isolated from the venom of a tarantula spider and known to block mechanically activated currents (Suchyna et al., 2000), has been shown to inhibit the Piezol channel in the low micromolar concentrations (Bae et al., 2011; Bagriantsev et al., 2014). Mechanistically, GsMTx4 acts on the extracellular side as a channel gating modifier to modulate the arrangements of membrane lipids in the surroundings of the channel protein and thereby decreases the efficiency of force transduction from the lipid bilayer to the channel (Suchyna et al., 2000; Gnanasambandam et al., 2017). Ruthenium red (RR), a polycationic ion, can also inhibit the Piezo1 channel-mediated mechanically activated currents with an $\mathrm{IC}_{50}$ (the concentration causing 50\% inhibition of the response) of $5.4 \mu \mathrm{M}$, which was shown at the Drosophila Piezo channel, and $\mathrm{RR}$ is thought to be an open channel blocker (Coste et al., 2012). Gadolinium ion $\left(\mathrm{Gd}^{3+}\right)$ in the micromolar concentrations is known to inhibit the Piezo1 channel (Cinar et al., 2015). These negative allosteric modulators or inhibitors are lack of the specificity towards the Piezol channel (Bowman et al., 2007). Nonetheless, they provide useful pharmacological tools, in combination with genetic means, to better understand the role of the Piezol channel in physiological and pathological processes.

The expression of the Piezol channel has been shown in an increasing number of cell types in various tissues and organs, 
including neurons, astrocytes, smooth muscle cells, endothelial cells, epithelial cells, red blood cells, immune cells, periodontal ligament cells, neural progenitor cells, mesenchymal stem cells, and embryonic stem cells (e.g., Li et al., 2014; Pathak et al., 2014; Jin et al., 2015; Gudipaty et al., 2017; Murthy et al., 2017; Del Marmol et al., 2018; Friedrich et al., 2019; Mousawi et al., 2019; Solis et al., 2019; Song et al., 2019; Velasco-Estevez et al., 2019). The Piezo1 channel is mainly located in the plasma membrane (Coste et al., 2010; Coste et al., 2012; Miyamoto et al., 2014; Hung et al., 2016). Some evidence suggests that the Piezol channel is also present in the membrane of endoplasmic reticulum (McHugh et al., 2010) and in the cytoplasmic compartments near the nucleus (Miyamoto et al., 2014) and nuclear envelope (Gudipaty et al., 2017). A large number of recent studies have disclosed a critical role for the cell surface Piezol channel or, more specifically, Piezol-mediated $\mathrm{Ca}^{2+}$ influx, in the regulation of a multiple of cell functions (e.g., Li et al., 2014; Pathak et al., 2014; Cinar et al., 2015; Hung et al., 2016; Gudipaty et al., 2017; Del Marmol et al., 2018; Friedrich et al., 2019; Mousawi et al., 2019; Solis et al., 2019; Song et al., 2019; VelascoEstevez et al., 2019; see a recent review by Xiao, 2019). As discussed next, accumulating evidence supports that ATP release and subsequent activation of the $\mathrm{P} 2 \mathrm{X}$ and/or $\mathrm{P} 2 \mathrm{Y}$ receptors are critical in mediating Piezol channel-dependent mechanoregulation.

\section{Stretch-Induced Piezo1-Dependent Adenosine Triphosphate Release From Urothelial Cells and Regulation of Bladder Function}

It is known that as the urinary bladder distends, the urothelial cells become stretched and, as a result, release ATP, which in turn excites the innervating pelvic nerve afferents (Ferguson et al., 1997; Vlaskovska et al., 2001; Beckel et al., 2015). The P2X3 receptor is expressed in the pelvic nerves, and the excitability of the pelvic nerve afferents induced by bladder distension was strongly attenuated in the P2X3-knockout mice, supporting a major role of the $\mathrm{P} 2 \mathrm{X} 3$ receptor in transducing ATP release from urothelial cells to excitation of the pelvic nerve afferents (Vlaskovska et al., 2001). Both VNUT-dependent vesicular ATP release via exocytosis and ATP efflux through the CALHM1 and pannexin-1 hemi-channels have been shown to mediate ATP release from urothelial cells in response to mechanical forces (Beckel et al., 2015; Nakagomi et al., 2016; Sana-Ur-Rehman et al., 2017). Furthermore, transient receptor potential (TRP) channels, particularly the TRPV4 channel, were suggested to sense mechanical stretch to induce ATP release from urothelial cells (Mochizuki et al., 2009; Merrill et al., 2016). However, compelling evidence indicates that mechanical activation of the TRPV4 channel is indirect, depending on mechanical induction of phospholipase A2-mediated generation of arachidonic acid and/or P450 epoxygenase-mediated generation of $5^{\prime}, 6^{\prime}$-epoxyeicosatrienoic acid from arachidonic acid (Vriens et al., 2004; Berna-Erro et al., 2017). Thus, the molecular mechanism that directly senses mechanical stimuli to trigger ATP release from urothelial cells remained elusive. A recent study has shown expression of the Piezol channel in urothelial cells from both human and mouse bladders (Miyamoto et al., 2014). In addition, membrane stretch induced a $\mathrm{Ca}^{2+}$ influx-dependent increase in the $\left[\mathrm{Ca}^{2+}\right]_{\mathrm{i}}$ in mouse urothelial cells, and such $\mathrm{Ca}^{2+}$ response was strongly attenuated by treatment with GsMTx 4 or small interference RNA (siRNA)-mediated knockdown of the Piezol expression. The same study has further found that stretch stimulated ATP release from mouse urothelial cells. Importantly, stretch-induced ATP release was dependent of extracellular $\mathrm{Ca}^{2+}$ and was suppressed by treatment with GsMTx4 or by siRNAmediated knockdown of the Piezol expression. This recent study, taken together with the previous study identifying the $\mathrm{P} 2 \mathrm{X} 3$ receptor in coupling urothelial ATP release to pelvic nerve afferent activation (Vlaskovska et al., 2001), supports the notion that the Piezol channel in urothelial cells sense the bladder distension and triggers ATP release from urothelial cells and that ATP in turn acts as a paracrine signal excites the pelvic nerve afferents via activation of the $\mathrm{P} 2 \mathrm{X} 3$ receptor (Figure 2A). In other words, the Piezo1 channel in urothelial cells and P2X3
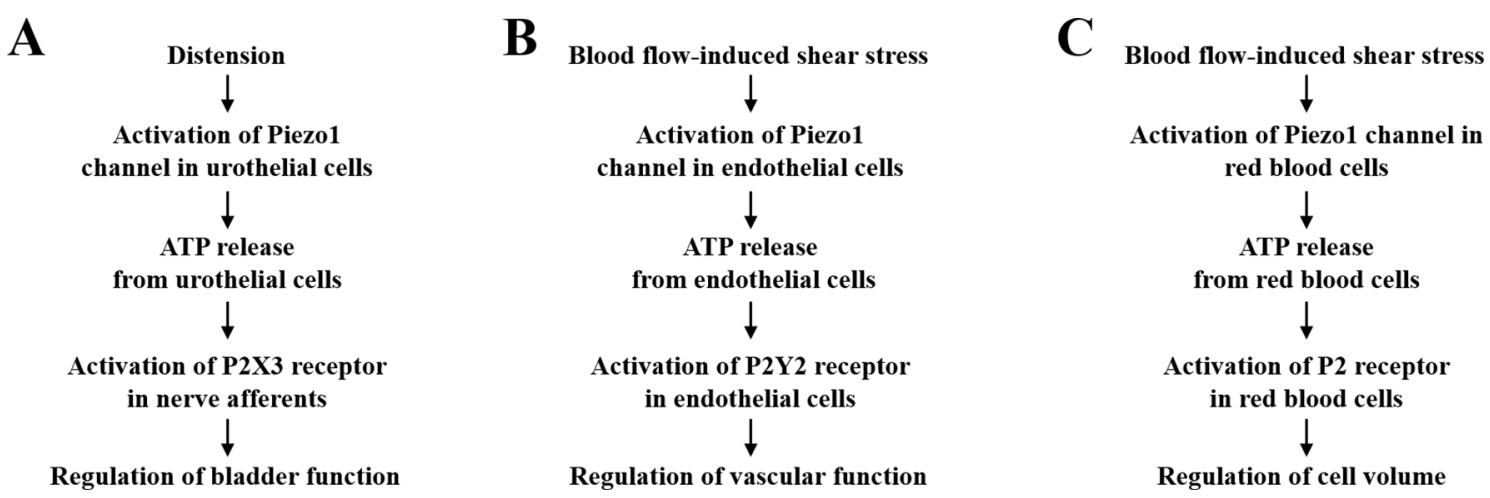

FIGURE 2 | Adenosine triphosphate (ATP) release and activation of P2 receptors in Piezo1 channel-dependent mechanoregulation. (A) The Piezo1 channel in urothelial cells senses mechanical forces resulting from bladder distension and induces urothelial cells to release ATP, which in turn acts as a paracrine signal to excite the pelvic nerve afferents by activating the P2X3 receptor. Such signaling mechanism is critical for maintaining the normal bladder function. (B) The Piezo1 channel in endothelial cells mediates blood flow-induced release of ATP that serves an autocrine signal acting on the P2Y2 receptor to regulate vascular function and blood pressure. (C). The Piezo1 channel in red blood cells mediates shear stress-induced release of ATP as an autocrine signal to activate yet identified P2 receptor(s) to regulate cell volume. See text for various molecular mechanisms that are known to mediate ATP release. 
receptor in sensory neurons are important duo players, linked by ATP release from urothelial cells, to maintain the normal bladder function.

\section{Shear Stress-Induced Piezo1-Dependent Adenosine Triphosphate Release From Endothelial Cells and Regulation of Vascular Function}

The vascular endothelium experiences dynamic blood flowinduced shear stress. It is well recognized that the ability of endothelial cells to sense and respond to shear stress is vital for development, function, and disease of the vascular system (Hahn and Schwartz, 2009; Tarbell et al., 2014; Baeyens et al., 2016). ATP release from endothelial cells in response to shear stress has been well documented, and there is compelling evidence to support a critical role of the pannexin-1 hemi-channel in mediating shear stress-induced ATP release (Wang et al., 2015; Wang et al., 2016; Sathanoori et al., 2017). A recent study has shown that ATP released from endothelial cells upon exposure to shear stress serves as a paracrine signal that activates the $\mathrm{P} 2 \mathrm{Y} 2$ receptor and downstream signaling pathways, including endothelial nitric oxide synthase to generate nitric oxide (NO), to induce vasodilation (Wang et al., 2015). Consistently, endothelium-specific deletion of the P2Y2 receptor expression in mice led to loss of blood flow-induced vasodilation, resulting in hypertension (Wang et al., 2015). A more recent study from the same group has examined the role of the Piezo1 channel in mediating shear stress-induced ATP release from endothelial cells (Wang et al., 2016). Exposing endothelial cells to shear stress or Yodal induced robust $\mathrm{Ca}^{2+}$ responses and ATP release, both of which were significantly attenuated by siRNAmediated knockdown of the Piezo1 expression. ATP release induced by shear stress or Yoda1 was also suppressed by siRNAmediated reduction in the expression of pannexin-1 or pannexin-2, indicating that shear stress-induced Piezol-dependent ATP release is at least in part mediated by the pannexin hemi-channels (Wang et al., 2016). Perfusion of the mouse mesenteric arteries or exposure to Yodal induced vasodilation, which was impaired by endothelium-specific deletion of the Piezol expression. Furthermore, endothelium-specific and conditional knockout of the Piezo1 expression led to elevated blood pressure in mice (Wang et al., 2016), as observed for endothelium-specific and conditional knockout of the P2Y2 receptor (Wang et al., 2015). Collectively, these studies provide compelling evidence to support a vital role of the Piezo1 channel in mediating blood flow-induced release of ATP from endothelial cells as an autocrine signal to regulate the vascular function via activating the $\mathrm{P} 2 \mathrm{Y} 2$ receptor (Figure 2B).

\section{Shear Stress-Induced Piezo1-Dependent Adenosine Triphosphate Release From Red Blood Cells and Regulation of Cell Volume}

Like endothelial cells, red blood cells in circulation are exposed to considerable flow-induced shear stress. Hereditary stomatocytosis and hereditary xerocytosis are rare genetic disorders characterized by red blood cell dehydration. Several gain-of-function mutations in the Piezol channel have been shown to be causatively associated these conditions, highlighting a crucial role of the Piezol channel in maintaining the normal red blood cell homeostasis (Zarychanski et al., 2012; Albuisson et al., 2013; Bae et al., 2013; Glogowska et al., 2017; Andolfo et al., 2018; Ma et al., 2018). Both human and mouse red blood cells are reported to express the Piezol channel on the cell surface. Interestingly, membrane stretch elicited strong $\mathrm{Ca}^{2+}$ influxdependent increase in the $\left[\mathrm{Ca}^{2+}\right]_{\mathrm{i}}$ in red blood cells isolated from wild-type mice, but not from mice with conditional knockout of the Piezol expression (Cahalan et al., 2015). Similarly, exposure to Yodal induced Piezo1-dependent $\mathrm{Ca}^{2+}$ entry in mouse red blood cells (Cahalan et al., 2015). Fluid flow-induced shear stress also elicited robust $\mathrm{Ca}^{2+}$ influx in human red blood cells, which was significantly suppressed by treatment with GsMTx4, RR or $\mathrm{Gd}^{3+}$ (Cinar et al., 2015). Furthermore, genetic deletion of the Piezo1 expression led to red blood cell over-hydration and increased mechanical fragility both in vitro and in vivo. Conversely, Yoda1induced activation of the Piezol channel caused red blood cell dehydration (Cahalan et al., 2015). These findings demonstrate an indispensable role of the Piezol channel in regulating red blood cell function and reveal the Piezol channel as a promising target for the development of therapeutics to treat hereditary stomatocytosis and hereditary xerocytosis.

It is long known that red blood cells release ATP in response to mechanical stimuli, such as osmotic stress (Petruzzi et al., 1994) and shear stress (Wan et al., 2008). A previous study showed that ATP release under in vitro conditions remained constant in response to shear stress below a certain threshold, but increased significantly above the threshold, which was accompanied with cellular deformation (Wan et al., 2008). A subsequent study provides evidence to suggest that the pannexin-1 hemi-channel is the main pathway mediating ATP release induced by shear stress both above and below the threshold, whereas the CFTR is engaged in deformation-dependent ATP release (Forsyth et al., 2011). A recent study shows that shear stress-induced ATP release was strongly correlated with extracellular $\mathrm{Ca}^{2+}$ concentration (Cinar et al., 2015). Shear stress-induced ATP release as well as $\mathrm{Ca}^{2+}$ influx in human red blood cells was attenuated by treatment with GsMTx4, RR or Gd ${ }^{3+}$ (Cinar et al., 2015). These results suggest that the Piezo1 channel is important in mediating induction by shear stress of ATP release from red blood cells (Figure 2C). Several ATP-sensitive P2 receptors, including P2X1, P2X7, and P2Y1, P2Y11 are expressed in red blood cells, and evidence exists to support that activation of these P2 receptors in red blood cells stimulates a number of signaling pathways that is critical for cell functions, including cell volume regulation (Sluyter, 2015). However, it has not been ascertained which P2 receptor(s) participate(s) in Piezo1-dependent regulation of red blood cell functions.

\section{Piezo1-Dependent Adenosine Triphosphate Release From Mesenchymal Stem Cells and Regulation of Cell Migration}

Mesenchymal stem cells (MSCs), which have promising applications in tissue regeneration and cell-based therapies, are highly mechanosensitive (Engler et al., 2006; Riddle et al., 
2007; Shih et al., 2011; Choi et al., 2012; Yang et al., 2012; Yuan et al., 2012; Suhr et al., 2013; Yuan et al., 2013; Chen et al., 2018; Goetzke et al., 2018; Li et al., 2018). It is well recognized that MSCs release ATP in response to mechanical stimulation both in vitro and in vivo (Riddle et al., 2007; Sun et al., 2013; Weihs et al., 2014). It is also known that several P2X and P2Y receptors are expressed in MSCs and mediate ATP-induced regulation of cell proliferation, migration, and differentiation (Coppi et al., 2007; Riddle et al., 2007; Sun et al., 2013; Peng et al., 2016; Jiang et al., 2017a; Jiang et al., 2017b). A previous study using bone marrow-derived MSCs suggests that fluid flow-induced ATP release via the pannexin hemi-channels and subsequent activation of the ATP-sensitive $\mathrm{P} 2 \mathrm{Y}$ receptors increased cell proliferation (Riddle et al., 2007). A more recent study shows that shockwave-induced ATP release via undefined release mechanisms and subsequent activation of the $\mathrm{P} 2 \mathrm{X} 7$ receptor stimulated osteogenic differentiation (Sun et al., 2013). The expression of the Piezo1 channel has been documented in several very recent studies using MSCs from different species and tissues (Gao et al., 2017; Sugimoto et al., 2017; Mousawi et al., 2019). Our recent study shows that Yodal-induced activation of the Piezo1 channel in human dental pulp MSC promoted migration, which was suppressed by siRNA-mediated knockdown of the Piezo1 expression (Mousawi et al., 2019). More importantly, Yoda1-induced activation of the Piezol channel stimulated ATP release from human dental pulp MSCs (Mousawi et al., 2019). Yoda1-induced Piezo1-dependent increase in cell migration was inhibited by treatment with apyrase, a scavenger of extracellular ATP, and also with PPADS, a P2 receptor generic antagonist. Taken together, these results support the notion that activation of the Piezol channel enhances MSC migration via inducing release of ATP as an autocrine signal that activates the $\mathrm{P} 2$ receptors. Our previous study has identified P2X7, P2Y1, and P2Y11 as the major $\mathrm{P} 2$ receptors that participate in mediating ATP-induced stimulation of human dental pulp MSC migration (Peng et al., 2016). It is highly interesting to examine the role of ATP release and the P2 receptors in Piezo1-dependent mechanoregulation of MSC functions such as differentiation and migration.

\section{Adenosine Triphosphate Release and P2 Receptor as a Common Signaling Mechanism in Piezo1 Channel-Dependent Mechanoregulation?}

As mentioned above, recent studies demonstrate expression of the Piezol channel in many different types of mechanosensitive cells with an important role in the mechanoregulation of attendant cell functions. The majority, if not all, of these cells, are known to express the $\mathrm{P} 2 \mathrm{X} / \mathrm{P} 2 \mathrm{Y}$ receptors that are important in mediating ATP-induced regulation of their functions. This raises the perspective that ATP release integrates the Piezol channel and $\mathrm{P} 2$ receptor as a more common signaling mechanism in the mechanoregulation of cell functions.

The expression of the Piezo 1 channel is required for alignment of endothelial cells in response to shear stress (Li et al., 2014; Ranade et al., 2014). Similarly, the P2Y2 receptor in endothelial cells plays an important role in mediating shear stress-induced cell alignment (Sathanoori et al., 2017). It is interesting to investigate whether shear stress-induced ATP release couples the Piezo1 and the P2Y2 receptor in the regulation of vascular development. Another recent study shows that shear stress induces ATP release from red blood cells, on one hand, and an increase in the $\left[\mathrm{Ca}^{2+}\right]_{\mathrm{i}}$ and NO generation in endothelial cells and formation of inter-endothelial junctions, on the other. These shear stress-induced responses or effects both in red blood cells and endothelial cells were prevented by pharmacological inhibition and genetic depletion of the pannexin-1 channel on red blood cells (Xu et al., 2017). It is unknown whether shear stress-induced Piezo1-dependent ATP release from red blood cells acts as a paracrine signal to induce $\mathrm{Ca}^{2+}$ signaling in endothelial cells via activating the $\mathrm{P} 2 \mathrm{X} / \mathrm{P} 2 \mathrm{Y}$ receptors.

As discussed above, ATP release coupling of the Piezol channel in urothelial cells and the P2X3 receptor in the pelvic nerve afferents is important in maintaining the normal bladder function. Such a signaling mechanism may also play an important role in mediating dentinal pain. It is known that dentinal fluidinduced odontoblast deformation can evoke dentinal pain. A recent electrophysiological study shows that pressure-induced odontoblast deformation elicited inward currents that caused membrane depolarization and induced action potentials in co-cultured isolectin IB4-negative medium-sized trigeminal ganglion neurons (Sato et al., 2018). Furthermore, such inward currents were significantly attenuated by treatment with NF110, a P2X3 receptor antagonist, or with GsMTx4 as well as with a cocktail of TRP channel inhibitors (Sato et al., 2018). It is thus hypothesized that Piezol/TRP-dependent ATP release from odontoblasts in response to mechanical stimulation excites myelinated $\mathrm{A} \delta$ neurons via activating the $\mathrm{P} 2 \mathrm{X} 3$ receptor, thereby forming a signaling mechanism generating dentinal pain.

Cancer cells in the metastasis process encounter mechanical forces such as compression from the surrounding extracellular matrix and cells in the primary site, invasion into neighboring tissues, intravasation and extravasation through endothelial cells, micro-metastasis at target tissues or organs. They also experience blood flow-induced shear stress during circulation in the blood stream. It is conceivable that mechanical forces influence cancer cell migration, invasiveness, and metastasis. Consistently, several recent studies provide increasing evidence to show that activation of the Piezol channel stimulates cell proliferation in gastric cancer cells (Zhang et al., 2018), and enhances cell migration in gastric cancer cells (Yang et al., 2014; Zhang et al., 2018) and malignant MCF-7 breast cancer cells (Li et al., 2015) but reduces non-small cell lung cancer progression and cell migration (Huang et al., 2019). Compelling evidence already exists to support that extracellular ATP can regulate cancer cell migration, invasiveness, and metastasis via activating the P2X7, P2Y2 or P2Y11 receptors (Jelassi et al., 2011; Jelassi et al., 2013; Schumacher et al., 2013; Chadet et al., 2014; Roger et al., 2015; Khalid et al., 2017). Particularly, it was shown that ATP released from platelets bound to the circulating cancer cells and consequently activates the $\mathrm{P} 2 \mathrm{Y} 2$ receptor on endothelial cells to promote formation of inter-endothelial junctions for cancer cell migration (Schumacher et al., 2013). As discussed above, shear stress can induce ATP release from red blood cells. It is 
attractive to speculate that shear stress-induced ATP release from red blood cells acts as a paracrine signal to induce formation of inter-endothelial junctions via activating the $\mathrm{P} 2 \mathrm{X} / \mathrm{P} 2 \mathrm{Y}$ receptors in endothelial cells and thereby facilities intravasation and extravasation of cancer cells.

\section{CONCLUDING REMARKS}

It is evident from the discussion above that accumulating evidence supports an important role of ATP release as an autocrine and/or paracrine signal and subsequent activation of the P2 receptors in Piezol channel-dependent mechanoregulation of cell functions and associated physiological processes (Figure 2). As illustrated by hereditary stomatocytosis and hereditary xerocytosis, alterations in such signaling mechanisms resulting from mutations in the Piezol channel in red blood cells can lead to cell dysfunction and severe human diseased conditions. Studies so far support the Piezol channel as an intrinsic mechanosensor to trigger ATP release in response to mechanical stimulation. However, it remains unknown how activation of the

\section{REFERENCES}

Abbracchio, M. P., Burnstock, G., Verkhratsky, A., and Zimmermann, H. (2009). Purinergic signalling in the nervous system: an overview. Trends Neurosci. 32, 19-29. doi: 10.1016/j.tins.2008.10.001

Albuisson, J., Murthy, S. E., Bandell, M., Coste, B., Louis-Dit-Picard, H., Mathur, J., et al. (2013). Dehydrated hereditary stomatocytosis linked to gain-of-function mutations in mechanically activated PIEZO1 ion channels. Nat. Commun. 4, 1884. doi: 10.1038/ncomms 2899

Alves, M., Beamer, E., and Engel, T. (2018). The metabotropic purinergic P2Y receptor family as novel drug target in epilepsy. Front. Pharmacol. 9, 193. doi: 10.3389/fphar.2018.00193

Andolfo, I., Manna, F., De Rosa, G., Rosato, B. E., Gambale, A., Tomaiuolo, G., et al. (2018). PIEZO1-R1864H rare variant accounts for a genetic phenotypemodifier role in dehydrated hereditary stomatocytosis. Haematologica 103, e94-e97. doi: 10.3324/haematol.2017.180687

Berna-Erro, A., Izquierdo-Serra, M., Sepúlveda, R. V., Rubio-Moscardo, F., Doñate-Macián, P., Serra, S. A., et al. (2017). Structural determinants of 5'6'-epoxyeicosatrienoic acid binding to and activation of TRPV4 channel. Sci. Rep 7, 10522. doi: 10.1038/s41598-017-11274-1

Bae, C., Sachs, F., and Gottlieb, P. A. (2011). The mechanosensitive ion channel Piezol is inhibited by the peptide GsMTx4. Biochemistry 50, 6295-6300. doi: 10.1021/bi200770q

Bae, C., Gnanasambandam, R., Nicolai, C., Sachs, F., and Gottlieb, P. A. (2013). Xerocytosis is caused by mutations that alter the kinetics of the mechanosensitive channel PIEZO1. Proc. Natl. Acad. Sci. U. S. A. 110, E1162E1168. doi: 10.1073/pnas.1219777110

Baeyens, N., Bandyopadhyay, C., Coon, B. G., Yun, S., and Schwartz, M. A. (2016). Endothelial fluid shear stress sensing in vascular health and disease. J. Clin. Invest 126, 821-828. doi: 10.1172/JCI83083

Bagriantsev, S. N., Gracheva, E. O., and Gallagher, P. G. (2014). Piezo proteins: regulators of mechanosensation and other cellular processes. J Biol Chem 289, 31673-31681. doi: 10.1074/jbc.R114.612697

Beckel, J. M., Daugherty, S. L., Tyagi, P., Wolf-Johnston, A. S., Birder, L. A., Mitchell, C. H., et al. (2015). Pannexin 1 channels mediate the release of ATP into the lumen of the rat urinary bladder. J. Physiol. 593, 1857-1871. doi: 10.1113/jphysiol.2014.283119

Bowman, C. L., Gottlieb, P. A., Suchyna, T. M., Murphy, Y. K., and Sachs, F. (2007). Mechanosensitive ion channels and the peptide inhibitor GsMTx-4: history, properties, mechanisms and pharmacology. Toxicon. 49, 249-270. doi: 10.1016/j.toxicon.2006.09.030
Piezo1 channel regulates the ATP release mechanisms. Finally, more investigations are required to determine whether the Piezo1 channel and P2 receptors coupled by ATP release form a common signaling mechanism in transducing mechanical force information to regulation of cell functions.

\section{AUTHOR CONTRIBUTIONS}

All authors contributed to the development of the concept. L-HJ wrote the manuscript. All the authors commented and approved the manuscript.

\section{ACKNOWLEDGMENTS}

The research works from the authors' laboratory were supported by the Disciplinary Group of Psychology and Neuroscience Xinxiang Medical University (2016PN-KFKT-06) and visiting professorship from University of Tours to LHJ, and a $\mathrm{PhD}$ studentship from Kuwait High Commission to FM.

Cahalan, S. M., Lukacs, V., Ranade, S. S., Chien, S., Bandell, M., and Patapoutian, A (2015). Piezo1 links mechanical forces to red blood cell volume. Elife 4. doi: 10.7554/eLife.07370

Caseley, E. A., Muench, S. P., Roger, S., Mao, H. J., Baldwin, S. A., and Jiang, L. H. (2014). Non-synonymous single nucleotide polymorphisms in the P2X receptor genes: association with diseases, impact on receptor functions and potential use as diagnosis biomarkers. Int. J. Mol. Sci. 15, 13344-13371. doi: 10.3390/ ijms150813344

Cekic, C., and Linden, J. (2016). Purinergic regulation of the immune system. Nat. Rev. Immunol. 16, 177-192. doi: 10.1038/nri.2016.4

Chadet, S., Jelassi, B., Wannous, R., Angoulvant, D., Chevalier, S., Besson, P., et al. (2014). The activation of P2Y2 receptors increases MCF-7 breast cancer cells migration through the MEK-ERK1/2 signalling pathway. Carcinogenesis 35, 1238-1247. doi: 10.1093/carcin/bgt493

Chen, J., Tan, Z., Zeng, L., Zhang, X., He, Y., Gao, W., et al. (2013). Heterosynaptic long-term depression mediated by ATP released from astrocytes. Glia 61, 178191. doi: 10.1002/glia.22425

Chen, X., Liu, Y., Ding, W., Shi, J., Li, S., Liu, Y., et al. (2018). Mechanical stretchinduced osteogenic differentiation of human jaw bone marrow mesenchymal stem cells (hJBMMSCs) via inhibition of the NF-kappaB pathway. Cell Death Dis. 9, 207. doi: 10.1038/s41419-018-0279-5

Choi, D., Park, E., Jung, E., Cha, B., Lee, S., Yu, J., et al. (2019). Piezo1 incorporates mechanical force signals into the genetic program that governs lymphatic valve development and maintenance. JCI Insight 4. doi: 10.1172/ jci.insight. 125068

Choi, Y. S., Vincent, L. G., Lee, A. R., Dobke, M. K., and Engler, A. J. (2012). Mechanical derivation of functional myotubes from adipose-derived stem cells. Biomaterials 33, 2482-2491. doi: 10.1016/j.biomaterials.2011.12.004

Cinar, E., Zhou, S., DeCourcey, J., Wang, Y., Waugh, R. E., and Wan, J. (2015). Piezol regulates mechanotransductive release of ATP from human RBCs. Proc. Natl. Acad. Sci. U. S. A. 112, 11783-11788. doi: 10.1073/pnas.1507309112

Coppi, E., Pugliese, A. M., Urbani, S., Melani, A., Cerbai, E., Mazzanti, B., et al. (2007). ATP modulates cell proliferation and elicits two different electrophysiological responses in human mesenchymal stem cells. Stem Cells 25, 1840-1849. doi: 10.1634/stemcells.2006-0669

Coste, B., Mathur, J., Schmidt, M., Earley, T. J., Ranade, S., Petrus, M. J., et al. (2010). Piezo1 and Piezo2 are essential components of distinct mechanically activated cation channels. Science 330, 55-60. doi: 10.1126/science.1193270

Coste, B., Xiao, B., Santos, J. S., Syeda, R., Grandl, J., Spencer, K. S., et al. (2012). Piezo proteins are pore-forming subunits of mechanically activated channels. Nature 483, 176-181. doi: 10.1038/nature10812 
Del Marmol, J. I., Touhara, K. K., Croft, G., and MacKinnon, R. (2018). Piezo1 forms a slowly-inactivating mechanosensory channel in mouse embryonic stem cells. Elife 7. doi: 10.7554/eLife.33149

Di Virgilio, F., Sarti, A. C., Falzoni, S., De Marchi, E., and Adinolfi, E. (2018). Extracellular ATP and P2 purinergic signalling in the tumour microenvironment. Nat. Rev. Cancer 18, 601-618. doi: 10.1038/s41568-018-0037-0

Ellefsen, K. L., Holt, J. R., Chang, A. C., Nourse, J. L., Arulmoli, J., Mekhdjian, A. H., et al. (2019). Myosin-II mediated traction forces evoke localized Piezo1-dependent Ca2+ flickers. Commun. Biol. 2, 298. doi: 10.1038/ s42003-019-0514-3

Engler, A. J., Sen, S., Sweeney, H. L., and Discher, D. E. (2006). Matrix elasticity directs stem cell lineage specification. Cell 126, 677-689. doi: 10.1016/j. cell.2006.06.044

Evans, E. L., Cuthbertson, K., Endesh, N., Rode, B., Blythe, N. M., Hyman, A. J., et al. (2018). Yodal analogue (Dookul) which antagonizes Yodal-evoked activation of Piezol and aortic relaxation. Br. J. Pharmacol. 175, 1744-1759. doi: 10.1111/bph.14188

Ferguson, D. R., Kennedy, I., and Burton, T. J. (1997). ATP is released from rabbit urinary bladder epithelial cells by hydrostatic pressure changes-a possible sensory mechanism? J. Physiol. 505 (Pt 2), 503-511. doi: 10.1111/j.1469-7793.1997.503bb.x

Fields, R. D., and Burnstock, G. (2006). Purinergic signalling in neuron-glia interactions. Nat. Rev. Neurosci. 7, 423-436. doi: 10.1038/nrn1928

Fields, R. D., and Ni, Y. (2010). Nonsynaptic communication through ATP release from volume-activated anion channels in axons. Sci. Signal. 3, ra73. doi: 10.1126/scisignal.2001128

Forsyth, A. M., Wan, J., Owrutsky, P. D., Abkarian, M., and Stone, H. A. (2011). Multiscale approach to link red blood cell dynamics, shear viscosity, and ATP release. Proc. Natl. Acad. Sci. U. S. A. 108, 10986-10991. doi: 10.1073/ pnas. 1101315108

Friedrich, E. E., Hong, Z., Xiong, S., Zhong, M., Di, A., Rehman, J., et al. (2019). Endothelial cell Piezol mediates pressure-induced lung vascular hyperpermeability via disruption of adherens junctions. Proc. Natl. Acad. Sci. U. S. A. 116, 12980-12985. doi: 10.1073/pnas.1902165116

Gao, Q., Cooper, P. R., Walmsley, A. D., and Scheven, B. A. (2017). Role of Piezo channels in ultrasound-stimulated dental stem cells. J. Endod. 43, 1130-1136. doi: 10.1016/j.joen.2017.02.022

Geisler, J. C., Corbin, K. L., Li, Q., Feranchak, A. P., Nunemaker, C. S., and Li, C. (2013). Vesicular nucleotide transporter-mediated ATP release regulates insulin secretion. Endocrinology 154, 675-684. doi: 10.1210/en.2012-1818

Glogowska, E., Schneider, E. R., Maksimova, Y., Schulz, V. P., Lezon-Geyda, K., $\mathrm{Wu}$, J., et al. (2017). Novel mechanisms of PIEZO1 dysfunction in hereditary xerocytosis. Blood 130, 1845-1856. doi: 10.1182/blood-2017-05-786004

Gnanasambandam, R., Gottlieb, P. A., and Sachs, F. (2017). The kinetics and the permeation properties of Piezo channels. Curr. Top. Membr. 79, 275-307. doi: 10.1016/bs.ctm.2016.11.004

Goetzke, R., Sechi, A., De Laporte, L., Neuss, S., and Wagner, W. (2018). Why the impact of mechanical stimuli on stem cells remains a challenge. Cell Mol. Life Sci. 75, 3297-3312. doi: 10.1007/s00018-018-2830-Z

Gudipaty, S. A., Lindblom, J., Loftus, P. D., Redd, M. J., Edes, K., Davey, C. F., et al. (2017). Mechanical stretch triggers rapid epithelial cell division through Piezo1. Nature 543, 118-121. doi: 10.1038/nature21407

Hahn, C., and Schwartz, M. A. (2009). Mechanotransduction in vascular physiology and atherogenesis. Nat. Rev. Mol. Cell Biol. 10, 53-62. doi: 10.1038/ nrm 2596

Harada, Y., Kato, Y., Miyaji, T., Omote, H., Moriyama, Y., and Hiasa, M. (2018). Vesicular nucleotide transporter mediates ATP release and migration in neutrophils. J. Biol. Chem. 293, 3770-3779. doi: 10.1074/jbc.M117.810168

Huang, Z., Sun, Z., Zhang, X., Niu, K., Wang, Y., Zheng, J., et al. (2019). Loss of stretch-activated channels, PIEZOs, accelerates non-small cell lung cancer progression and cell migration. Biosci. Rep. 39. doi: 10.1042/BSR20181679

Hung, W. C., Yang, J. R., Yankaskas, C. L., Wong, B. S., Wu, P. H., Pardo-Pastor, C., et al. (2016). Confinement sensing and signal optimization via Piezol/PKA and myosin II pathways. Cell Rep. 15, 1430-1441. doi: 10.1016/j.celrep.2016.04.035

Iring, A., Jin, Y. J., Albarran-Juarez, J., Siragusa, M., Wang, S., Dancs, P. T., et al. (2019). Shear stress-induced endothelial adrenomedullin signaling regulates vascular tone and blood pressure. J. Clin. Invest. 130, 2775-2791. doi: 10.1172/ JCI123825
Jelassi, B., Chantome, A., Alcaraz-Perez, F., Baroja-Mazo, A., Cayuela, M. L., Pelegrin, P., et al. (2011). P2X7 receptor activation enhances SK3 channels- and cystein cathepsin-dependent cancer cells invasiveness. Oncogene 30, 21082122. doi: 10.1038/onc. 2010.593

Jelassi, B., Anchelin, M., Chamouton, J., Cayuela, M. L., Clarysse, L., Li, J., et al. (2013). Anthraquinone emodin inhibits human cancer cell invasiveness by antagonizing P2X7 receptors. Carcinogenesis 34, 1487-1496. doi: 10.1093/carcin/bgt099

Jiang, L. H., Mousawi, F., Yang, X., and Roger, S. (2017a). ATP-induced Ca2+signalling mechanisms in the regulation of mesenchymal stem cell migration. Cell Mol. Life Sci. 74, 3697-3710. doi: 10.1007/s00018-017-2545-6

Jiang, L. H., Hao, Y., Mousawi, F., Peng, H., and Yang, X. (2017b). Expression of P2 purinergic receptors in mesenchymal stem vells and their toles in extracellular nucleotide regulation of cell functions. J. Cell Physiol. 232, 287-297. doi: $10.1002 /$ jcp. 25484

Jin, Y., Li, J., Wang, Y., Ye, R., Feng, X., Jing, Z., et al. (2015). Functional role of mechanosensitive ion channel Piezol in human periodontal ligament cells. Angle Orthod. 85, 87-94. doi: 10.2319/123113-955.1

Khakh, B. S., and North, R. A. (2006). P2X receptors as cell-surface ATP sensors in health and disease. Nature 442, 527-532. doi: 10.1038/nature04886

Khalid, M., Brisson, L., Tariq, M., Hao, Y., Guibon, R., Fromont, G., et al. (2017). Carcinoma-specific expression of P2Y11 receptor and its contribution in ATPinduced purinergic signalling and cell migration in human hepatocellular carcinoma cells. Oncotarget 8, 37278-37290. doi: 10.18632/oncotarget.16191

Krugel, U. (2016). Purinergic receptors in psychiatric disorders. Neuropharmacology 104, 212-225. doi: 10.1016/j.neuropharm.2015.10.032

Lalo, U., Palygin, O., Rasooli-Nejad, S., Andrew, J., Haydon, P. G., and Pankratov, Y. (2014). Exocytosis of ATP from astrocytes modulates phasic and tonic inhibition in the neocortex. PLoS Biol. 12, e1001747. doi: 10.1371/journal.pbio.1001747

Lewis, A. H., and Grandl, J. (2015). Mechanical sensitivity of Piezol ion channels can be tuned by cellular membrane tension. Elife 4. doi: 10.7554/eLife.12088

Li, C., Rezania, S., Kammerer, S., Sokolowski, A., Devaney, T., Gorischek, A., et al. (2015). Piezol forms mechanosensitive ion channels in the human MCF-7 breast cancer cell line. Sci. Rep. 5, 8364. doi: 10.1038/srep08364

Li, J., Hou, B., Tumova, S., Muraki, K., Bruns, A., Ludlow, M. J., et al. (2014). Piezo1 integration of vascular architecture with physiological force. Nature 515, 279282. doi: 10.1038/nature 13701

Li, S., Wang, J., Han, Y., Li, X., Liu, C., Lv, Z., et al. (2018). Carbenoxolone inhibits mechanical stress-induced osteogenic differentiation of mesenchymal stem cells by regulating p38 MAPK phosphorylation. Exp. Ther. Med. 15, 2798-2803. doi: 10.3892/etm.2018.5757

Lin, Y. C., Guo, Y. R., Miyagi, A., Levring, J., MacKinnon, R., and Scheuring, S. (2019). Force-induced conformational changes in PIEZO1. Nature 573, 230 234. doi: 10.1038/s41586-019-1499-2

Ma, S., Cahalan, S., LaMonte, G., Grubaugh, N. D., Zeng, W., Murthy, S. E., et al. (2018). Common PIEZO1 allele in African populations causes RBC dehydration and attenuates plasmodium infection. Cell 173, 443-455. doi: 10.1016/j.cell.2018.02.047

Masuda, T., Ozono, Y., Mikuriya, S., Kohro, Y., Tozaki-Saitoh, H., Iwatsuki, K., et al. (2016). Dorsal horn neurons release extracellular ATP in a VNUTdependent manner that underlies neuropathic pain. Nat. Commun. 7, 12529. doi: $10.1038 /$ ncomms12529

McHugh, B. J., Buttery, R., Lad, Y., Banks, S., Haslett, C., and Sethi, T. (2010). Integrin activation by Fam38A uses a novel mechanism of R-Ras targeting to the endoplasmic reticulum. J. Cell Sci. 123, 51-61. doi: 10.1242/jcs.056424

Merrill, L., Gonzalez, E. J., Girard, B. M., and Vizzard, M. A. (2016). Receptors, channels, and signalling in the urothelial sensory system in the bladder. Nat. Rev. Urol. 13, 193-204. doi: 10.1038/nrurol.2016.13

Miras-Portugal, M. T., Menéndez-Méndez, A., Gómez-Villafuertes, R., Ortega, F., Delicado, E. G., Pérez-Sen, R., et al. (2019). Physiopathological role of the vesicular nucleotide transporter (VNUT) in the central nervous system: relevance of the vesicular nucleotide release as a potential therapeutic target. Front. Cell Neurosci. 13, 224. doi: 10.3389/fncel.2019.00224

Miyamoto, T., Mochizuki, T., Nakagomi, H., Kira, S., Watanabe, M., Takayama, Y., et al. (2014). Functional role for Piezo1 in stretch-evoked Ca2+ influx and ATP release in urothelial cell cultures. J. Biol. Chem. 289, 16565-16575. doi: 10.1074/jbc.M113.528638

Mochizuki, T., Sokabe, T., Araki, I., Fujishita, K., Shibasaki, K., Uchida, K., et al. (2009). The TRPV4 cation channel mediates stretch-evoked Ca2+ influx and 
ATP release in primary urothelial cell cultures. J. Biol. Chem. 284, 2125721264. doi: 10.1074/jbc.M109.020206

Moriyama, Y., Hiasa, M., Sakamoto, S., Omote, H., and Nomura, M. (2017). Vesicular nucleotide transporter (VNUT): appearance of an actress on the stage of purinergic signaling. Purinergic Signal 13, 387-404. doi: 10.1007/ s11302-017-9568-1

Mousawi, F., Peng, H., Li, J., Sreenivasan, P., Roger, S., Zhao, H., et al. (2019). Chemical activation of the Piezol channel drives mesenchymal stem cell migration via inducing ATP release and activation of $\mathrm{P} 2$ receptor purinergic signalling. Stem Cells. doi: 10.1002/stem.3114

Murthy, S. E., Dubin, A. E., and Patapoutian, A. (2017). Piezos thrive under pressure: mechanically activated ion channels in health and disease. Nat. Rev. Mol. Cell Biol. 18, 771-783. doi: 10.1038/nrm.2017.92

Nakagomi, H., Yoshiyama, M., Mochizuki, T., Miyamoto, T., Komatsu, R., Imura, Y., et al. (2016). Urothelial ATP exocytosis: regulation of bladder compliance in the urine storage phase. Sci. Rep. 6, 29761. doi: 10.1038/srep29761

North, R. A. (2002). Molecular physiology of P2X receptors. Physiol. Rev. 82, 1013-1067. doi: 10.1152/physrev.00015.2002

Nourse, J. L., and Pathak, M. M. (2017). How cells channel their stress: Interplay between Piezol and the cytoskeleton. Semin. Cell Dev. Biol. 71, 3-12. doi: 10.1016/j.semcdb.2017.06.018

Pankratov, Y., Lalo, U., Verkhratsky, A., and North, R. A. (2006). Vesicular release of ATP at central synapses. Pflugers Arch 452, 589-597. doi: 10.1007/ s00424-006-0061-x

Parpaite, T., and Coste, B. (2017). Piezo channels. Curr. Biol. 27, R250-R252. doi: 10.1016/j.cub.2017.01.048

Pathak, M. M., Nourse, J. L., Tran, T., Hwe, J., Arulmoli, J., Le, D. T., et al. (2014). Stretchactivated ion channel Piezol directs lineage choice in human neural stem cells. Proc. Natl. Acad. Sci. U. S. A. 111, 16148-16153. doi: 10.1073/pnas.1409802111

Peng, H., Hao, Y., Mousawi, F., Roger, S., Li, J., Sim, J. A., et al. (2016). Purinergic and store-operated $\mathrm{Ca} 2+$ signaling mechanisms in mesenchymal stem cells and their roles in ATP-induced stimulation of cell migration. Stem Cells 34, 2102-2114. doi: 10.1002/stem.2370

Petruzzi, E., Orlando, C., Pinzani, P., Sestini, R., Del Rosso, A., Dini, G., et al. (1994). Adenosine triphosphate release by osmotic shock and hemoglobin A1C in diabetic subjects' erythrocytes. Metabolism 43, 435-440. doi: 10.1016/0026-0495(94)90072-8

Ranade, S. S., Qiu, Z., Woo, S. H., Hur, S. S., Murthy, S. E., Cahalan, S. M., et al. (2014). Piezo1, a mechanically activated ion channel, is required for vascular development in mice. Proc. Natl. Acad. Sci. U. S. A. 111, 10347-10352. doi: 10.1073/pnas.1409233111

Riddle, R. C., Taylor, A. F., Rogers, J. R., and Donahue, H. J. (2007). ATP release mediates fluid flow-induced proliferation of human bone marrow stromal cells. J. Bone Miner Res. 22, 589-600. doi: 10.1359/jbmr.070113

Roger, S., Jelassi, B., Couillin, I., Pelegrin, P., Besson, P., and Jiang, L. H. (2015). Understanding the roles of the P2X7 receptor in solid tumour progression and therapeutic perspectives. Biochim. Biophys. Acta 1848, 2584-2602. doi: 10.1016/j.bbamem.2014.10.029

Sakamoto, S., Miyaji, T., Hiasa, M., Ichikawa, R., Uematsu, A., Iwatsuki, K., et al. (2014). Impairment of vesicular ATP release affects glucose metabolism and increases insulin sensitivity. Sci. Rep. 4, 6689. doi: 10.1038/srep06689

Sana-Ur-Rehman, H., Markus, I., Moore, K. H., Mansfield, K. J., and Liu, L. (2017). Expression and localization of pannexin-1 and CALHM1 in porcine bladder and their involvement in modulating ATP release. Am. J. Physiol. Regul. Integr. Comp. Physiol. 312, R763-R772. doi: 10.1152/ajpregu.00039.2016

Saotome, K., Murthy, S. E., Kefauver, J. M., Whitwam, T., Patapoutian, A., and Ward, A. B. (2018). Structure of the mechanically activated ion channel Piezol. Nature 554, 481-486. doi: 10.1038/nature25453

Sato, M., Ogura, K., Kimura, M., Nishi, K., Ando, M., Tazaki, M., et al. (2018). Activation of mechanosensitive transient receptor potential/Piezo channels in odontoblasts generates action potentials in cocultured isolectin B4-negative medium-sized trigeminal ganglion neurons. J. Endod. 44, 984-991. doi: 10.1016/j.joen.2018.02.020

Sathanoori, R., Bryl-Gorecka, P., Muller, C. E., Erb, L., Weisman, G. A., Olde, B., et al. (2017). P2Y2 receptor modulates shear stress-induced cell alignment and actin stress fibers in human umbilical vein endothelial cells. Cell Mol. Life Sci. 74, 731-746. doi: 10.1007/s00018-016-2365-0
Sawada, K., Echigo, N., Juge, N., Miyaji, T., Otsuka, M., Omote, H., et al. (2008). Identification of a vesicular nucleotide transporter. Proc. Natl. Acad. Sci. U. S. A.105, 5683-5686. doi: 10.1073/pnas.0800141105

Schumacher, D., Strilic, B., Sivaraj, K. K., Wettschureck, N., and Offermanns, S. (2013). Platelet-derived nucleotides promote tumor-cell transendothelial migration and metastasis via P2Y2 receptor. Cancer Cell 24, 130-137. doi: 10.1016/j.ccr.2013.05.008

Shih, Y. R., Tseng, K. F., Lai, H. Y., Lin, C. H., and Lee, O. K. (2011). Matrix stiffness regulation of integrin-mediated mechanotransduction during osteogenic differentiation of human mesenchymal stem cells. J. Bone Miner. Res. 26, $730-$ 738. doi: $10.1002 / j b m r .278$

Sluyter, R. (2015). P2X and P2Y receptor signaling in red blood cells. Front. Mol. Biosci. 2, 60. doi: 10.3389/fmolb.2015.00060

Song, Y., Li, D., Farrelly, O., Miles, L., Li, F., Kim, S. E., et al. (2019). The mechanosensitive ion channel Piezo inhibits axon regeneration. Neuron 102, 373-389. doi: 10.1016/j.neuron.2019.01.050

Solis, A. G., Bielecki, P., Steach, H. R., Sharma, L., Harman, C. C. D., Yun, S., et al. (2019). Mechanosensation of cyclical force by PIEZO1 is essential for innate immunity. Nature 573, 69-74. doi: 10.1038/s41586-019-1485-8

Suchyna, T. M., Johnson, J. H., Hamer, K., Leykam, J. F., Gage, D. A., Clemo, H. F., et al. (2000). Identification of a peptide toxin from Grammostola spatulata spider venom that blocks cation-selective stretch-activated channels. J. Gen. Physiol. 115, 583-598. doi: 10.1085/jgp.115.5.583

Sugimoto, A., Miyazaki, A., Kawarabayashi, K., Shono, M., Akazawa, Y., Hasegawa, T., et al. (2017). Piezo type mechanosensitive ion channel component 1 functions as a regulator of the cell fate determination of mesenchymal stem cells. Sci. Rep. 7, 17696. doi: 10.1038/s41598-017-18089-0

Suhr, F., Delhasse, Y., Bungartz, G., Schmidt, A., Pfannkuche, K., and Bloch, W. (2013). Cell biological effects of mechanical stimulations generated by focused extracorporeal shock wave applications on cultured human bone marrow stromal cells. Stem Cell Res. 11, 951-964. doi: 10.1016/j.scr.2013.05.010

Sun, D., Junger, W. G., Yuan, C., Zhang, W., Bao, Y., Qin, D., et al. (2013). Shockwaves induce osteogenic differentiation of human mesenchymal stem cells through ATP release and activation of P2X7 receptors. Stem Cells 31, 1170-1180. doi: 10.1002/stem.1356

Surprenant, A., and North, R. A. (2009). Signaling at purinergic P2X receptors. Annu. Rev. Physiol.71,333-359. doi: 10.1146/annurev.physiol.70.113006.100630

Syeda, R., Florendo, M. N., Cox, C. D., Kefauver, J. M., Santos, J. S., Martinac, B., et al. (2016). Piezol channels are inherently mechanosensitive. Cell Rep. 17, 1739-1746. doi: 10.1016/j.celrep.2016.10.033

Syeda, R., Xu, J., Dubin, A. E., Coste, B., Mathur, J., Huynh, T., et al. (2015). Chemical activation of the mechanotransduction channel Piezol. Elife 4. doi: 10.7554/eLife.07369

Tarbell, J. M., Simon, S. I., and Curry, F. R. (2014). Mechanosensing at the vascular interface. Annu. Rev. Biomed. Eng. 16, 505-532. doi: 10.1146/ annurev-bioeng-071813-104908

Taruno, A. (2018). ATP release channels. Int. J. Mol. Sci. 19 (3), E808. doi: 10.3390/ ijms 19030808

Velasco-Estevez, M., Rolle, S. O., Mampay, M., Dev, K. K., and Sheridan, G. K., (2019). Piezo1 regulates calcium oscillations and cytokine release from astrocytes. Glia. doi: 10.1002/glia.23709

Verkhratsky, A., and Burnstock, G. (2014). Biology of purinergic signalling: its ancient evolutionary roots, its omnipresence and its multiple functional significance. Bioessays 36, 697-705. doi: 10.1002/bies.201400024

Vlaskovska, M., Kasakov, L., Rong, W., Bodin, P., Bardini, M., Cockayne, D. A., et al. (2001). P2X3 knock-out mice reveal a major sensory role for urothelially released ATP. J Neurosci 21, 5670-5677. doi: 10.1523/JNEUROSCI.21-15-05670.2001

Vriens, J., Watanabe, H., Janssens, A., Droogmans, G., Voets, T., and Nilius, B. (2004). Cell swelling, heat, and chemical agonists use distinct pathways for the activation of the cation channel TRPV4. Proc Natl Acad Sci U S A 101, 396-401. doi: 10.1073/pnas.0303329101

Wang, L., Zhou, H., Zhang, M., Liu, W., Deng, T., Zhao, Q., et al. (2019). Structure and mechanogating of the mammalian tactile channel PIEZO2. Nature 573, 225-229. doi: 10.1038/s41586-019-1505-8

Wan, J., Ristenpart, W. D., and Stone, H. A. (2008). Dynamics of shear-induced ATP release from red blood cells. Proc. Natl. Acad. Sci. U. S. A. 105, 1643216437. doi: 10.1073/pnas.0805779105 
Wang, S., Chennupati, R., Kaur, H., Iring, A., Wettschureck, N., and Offermanns, S. (2016). Endothelial cation channel PIEZO1 controls blood pressure by mediating flow-induced ATP release. J. Clin. Invest. 126, 4527-4536. doi: 10.1172/JCI87343

Wang, S., Iring, A., Strilic, B., Albarran Juarez, J., Kaur, H., Troidl, K., et al. (2015). P2Y2 and Gq/11 control blood pressure by mediating endothelial mechanotransduction. J. Clin. Invest. 125, 3077-3086. doi: 10.1172/JCI81067

Wei, L., Syed Mortadza, S. A., Yan, J., Zhang, L., Wang, L., Yin, Y., et al. (2018). ATP-activated P2X7 receptor in the pathophysiology of mood disorders and as an emerging target for the development of novel antidepressant therapeutics. Neurosci. Biobehav. Rev. 87, 192-205. doi: 10.1016/j.neubiorev.2018.02.005

Weihs, A. M., Fuchs, C., Teuschl, A. H., Hartinger, J., Slezak, P., Mittermayr, R., et al. (2014). Shock wave treatment enhances cell proliferation and improves wound healing by ATP release-coupled extracellular signal-regulated kinase (ERK) activation. J. Biol. Chem. 289, 27090-27104. doi: 10.1074/jbc.M114.580936

Wu, J., Lewis, A. H., and Grandl, J. (2017). Touch, tension, and transduction - The function and regulation of Piezo ion channels. Trends. Biochem. Sci. 42, 57-71. doi: 10.1016/j.tibs.2016.09.004

Xiao, B. (2019). Levering mechanically activated Piezo channels for potential pharmacological intervention. Annu. Rev. Pharmacol. Toxicol. doi: 10.1146/ annurev-pharmtox-010919-023703

Xu, S., Li, X., LaPenna, K. B., Yokota, S. D., Huke, S., and He, P. (2017). New insights into shear stress-induced endothelial signalling and barrier function: cell-free fluid versus blood flow. Cardiovasc. Res. 113, 508-518. doi: 10.1093/cvr/cvx021

Yang, X., Cai, X., Wang, J., Tang, H., Yuan, Q., Gong, P., et al. (2012). Mechanical stretch inhibits adipogenesis and stimulates osteogenesis of adipose stem cells. Cell Prolif. 45, 158-166. doi: 10.1111/j.1365-2184.2011.00802.X

Yang, X. N., Lu, Y. P., Liu, J. J., Huang, J. K., Liu, Y. P., Xiao, C. X., et al. (2014). Piezol is as a novel trefoil factor family 1 binding protein that promotes gastric cancer cell mobility in vitro. Dig. Dis. Sci 59, 1428-1435. doi: 10.1007/ s10620-014-3044-3

Yu, T., Junger, W. G., Yuan, C., Jin, A., Zhao, Y., Zheng, X., et al. (2010). Shockwaves increase T-cell proliferation and IL-2 expression through ATP release, P2X7 receptors, and FAK activation. Am. J. Physiol. Cell. Physiol. 298, C457-C464. doi: 10.1152/ajpcell.00342.2009
Yuan, L., Sakamoto, N., Song, G., and Sato, M. (2012). Migration of human mesenchymal stem cells under low shear stress mediated by mitogen-activated protein kinase signaling. Stem Cells Dev. 21, 2520-2530. doi: 10.1089/ scd.2012.0010

Yuan, L., Sakamoto, N., Song, G., and Sato, M. (2013). Low-level shear stress induces human mesenchymal stem cell migration through the SDF-1/CXCR4 axis via MAPK signaling pathways. Stem Cells Dev. 22, 2384-2393. doi: $10.1089 / \mathrm{scd} .2012 .0717$

Zarychanski, R., Schulz, V. P., Houston, B. L., Maksimova, Y., Houston, D. S., Smith, B., et al. (2012). Mutations in the mechanotransduction protein PIEZO1 are associated with hereditary xerocytosis. Blood 120, 1908-1915. doi: 10.1182/ blood-2012-04-422253

Zhang, J., Zhou, Y., Huang, T., Wu, F., Liu, L., Kwan, J. S. H., et al. (2018). PIEZO1 functions as a potential oncogene by promoting cell proliferation and migration in gastric carcinogenesis. Mol. Carcinog. 57, 1144-1155. doi: 10.1002/mc.22831

Zhao, Q., Zhou, H., Li, X., and Xiao, B. (2019). The mechanosensitive Piezol channel: a three-bladed propeller-like structure and a lever-like mechanogating mechanism. FEBS J. 286, 2461-2470. doi: 10.1111/febs.14711

Zhao, Q., Zhou, H., Chi, S., Wang, Y., Wang, J., Geng, J., et al. (2018). Structure and mechanogating mechanism of the Piezol channel. Nature 554, 487-492. doi: 10.1038 /nature25743

Zimmermann, H., Zebisch, M., and Strater, N. (2012). Cellular function and molecular structure of ecto-nucleotidases. Purinergic Signal 8, 437-502. doi: $10.1007 / \mathrm{s} 11302-012-9309-4$

Conflict of Interest: The authors declare that the research was conducted in the absence of any commercial or financial relationships that could be construed as a potential conflict of interest.

Copyright (C) 2019 Wei, Mousawi, Li, Roger, Li, Yang and Jiang. This is an open-access article distributed under the terms of the Creative Commons Attribution License (CC $B Y)$. The use, distribution or reproduction in other forums is permitted, provided the original author(s) and the copyright owner(s) are credited and that the original publication in this journal is cited, in accordance with accepted academic practice. No use, distribution or reproduction is permitted which does not comply with these terms. 